\title{
Effects of a low-energy diet associated with egg supplementation on plasma cholesterol and lipoprotein levels in normal subjects: results of a cross-over study
}

\author{
By CHRISTIANE R. LACOMBE, GENEVIÈVE R. CORRAZE AND \\ MARYSE M. NIBBELINK \\ UA 644 CNRS, Université Paul Sabatier, Institut de Physiologie, Toulouse, France \\ AND DANIÈLE BOULZE \\ Ecole de Diététique, Toulouse, France
}

AND PHILIPPE DOUSTE-BLAZY AND RITA CAMARE

INSERM U 101, Université Paul Sabatier, CHU Purpan, Toulouse, France

(Received 29 November 1985 - Accepted 25 June 1986)

\begin{abstract}
1. The influence of a low-energy diet when associated with high-cholesterol intake was investigated in seventeen normal men during an 8-week cross-over study. The subjects were given a daily supplement of two whole eggs and two egg yolks (approximately $1 \mathrm{~g}$ cholesterol) either with their usual diet for 4 weeks or with a low-energy diet for 4 weeks. Each subject took part randomly in both dietary periods.

2. During the first part of the study, no changes occurred in the plasma cholesterol of the subjects with egg supplementation of the usual diet.

3 . In contrast, the low-energy diet and associated weight loss markedly decreased the tolerance to highcholesterol intake resulting in increased plasma cholesterol. The mean rise was $22.7 \%$ but with wide individual variations in the response. This was almost completely normalized when the subjects returned to their usual energy intake indicating the involvement of weight reduction in the increase observed.

4. Changes in low-density-lipoprotein (LDL) cholesterol were parallel to those of total plasma cholesterol with an increase following the low-energy diet and normalization after body-weight recovery.

5. The opposite effect was shown with the low-energy diet after previous adaptation to the consumption of four eggs per day. This dietary regimen resulted in a decrease in plasma cholesterol although it was not significant. Moreover, the lipoprotein profile was improved with a decrease in very-low-density-lipoprotein (VLDL) cholesterol and an increase in high-density-lipoprotein (HDL) cholesterol.

6. High-cholesterol intake induced significant changes in lipoprotein composition whatever the energy ration. LDL and HDL were enriched in cholesterol esters as early as the 1st month of egg supplementation of the diet.

7. Taken together, the results emphasize the possible adverse effect of slimming diets when associated with high-cholesterol intake. The existence of 'high-responders' to these dietary conditions calls for special attention to be paid to the cholesterol content of restricted diets.
\end{abstract}

Among the various risk factors involved in the development of cardiovascular disease, the diet is thought to be an important determinant. Special attention has been paid towards the amount and the nature of dietary lipids. Conflicting information has been obtained concerning cholesterol intake. Some studies indicate no consistent effect on plasma cholesterol (Slater et al. 1976; Kummerow et al. 1977; Porter et al. 1977; Flynn et al. 1979; Flaim et al. 1981) while others showed increased plasma cholesterol levels following cholesterol-rich diets (Beveridge et al. 1960; Mattson et al. 1972; Applebaum-Boyden et al. 1979; Tan et al. 1980; Mistry et al. 1981; Roberts et al. 1981; Schonfeld et al. 1982; Cole et al. 1983). In fact this controversy could be related to the variable response to increased dietary cholesterol. Taken together the results show the existence of 'responders' and 'non-responders' to dietary cholesterol. The ability to compensate for increased dietary cholesterol was seen to be related to the suppression of endogenous synthesis (Quintao et al. 1971; Nestel \& Payser, 1976; Lin \& Connor, 1980) more than to individual differences in intestinal absorption. 
Several studies focused on the role of other associated factors such as saturated and polyunsaturated fats. The effect of dietary cholesterol could be enhanced by diets rich in saturated fats (Bronsgeest-Schoute et al. 1979) while it was decreased by diets with a high polyunsaturated: saturated fatty acids ratio (Schonfeld et al. 1982).

From previous animal studies we suggested that dietary restriction may be an additional risk factor. Experiments carried out in rabbits (Lacombe et al. 1983) and in rats (Corraze et al. 1982a) demonstrated that the effect of a cholesterol-rich diet could be markedly enhanced when associated with dietary restriction. In both species, the additional hypercholesterolaemia was characterized by expansion of the $\beta$-very-low-density lipoproteins (VLDL) (Lacombe et al. 1983; Corraze et al. 1985a). These results showed the existence of an interaction between dietary cholesterol and energy deficiency resulting in increased plasma cholesterol. The fact that this phenomenon was observed in a species susceptible to, as well as in one highly resistant to hypercholesterolaemia and atherosclerosis, raised the question of the situation in humans.

The adverse effect of dietary restriction was rather unexpected since it is generally assumed that plethoric diets are a major cause in the development of obesity and maturity-onset diabetes, which are both associated with abnormalities in plasma lipoprotein patterns (Avogaro et al. 1978; Barrett-Connor et al. 1983). In contrast, weight loss was shown to reduce plasma cholesterol and triglyceride concentrations in obese subjects (Bolzano et al. 1979; Hendrikx et al. 1979; Taskinen \& Nikkila, 1979; Schouten et al. 1981; Wechsler et al. 1981; Wolf \& Grundy, 1983; Zimmerman et al. 1984). In these studies the lipoprotein pattern improved following weight reduction although some controversial results have been obtained for the high-density-lipoprotein (HDL) cholesterol level. Nevertheless, the effect of low-energy diets was studied only in obese subjects and the results could be different in normolipidaemic individuals. In fact Bolzano et al. (1979) and Hendrickx et al. (1979) reported that plasma cholesterol concentration increased in normolipidaemic subjects during fasting while it decreased in hypertriglyceridaemic subjects.

The present study was undertaken in order to investigate the existence of the adverse effect of low-energy diets when associated with high-cholesterol intake in humans as previously demonstrated in animals (Lacombe et al. 1983; Corraze et al. 1985a). This was carried out by a cross-over study in normal subjects living in a religious community.

\section{METHODS}

\section{Subjects}

The present study was carried out on a community of monks in order to obtain a relatively homogeneous group concerning their diet before the experiment, their physical activity and their way of life. In addition, in a community, dietary supervision was easier. Seventeen healthy men, without regular therapy, participated in the study. Informed consent was obtained from each subject before initiating the experiment and the study protocol was approved by the Human Ethics Committee. They were assigned randomly to two groups but several renunciations during the experiment resulted in a smaller size of group 2 .

Details of individual age, body mass index and plasma lipid concentrations are given in Table 1. Information concerning cigarette smoking and regular physical activity are also included. All subjects were within the normal body mass index range (Keys et al. 1972) and most of them had normal plasma cholesterol and triglycerides. Four subjects had plasma cholesterol near or above $2 \cdot 2 \mathrm{~g} / 1$ and only one had a triglyceride concentration in excess of $1.5 \mathrm{~g} / \mathrm{l}$. The two groups were compared using Student's $t$ test. In spite of a relatively higher level of plasma triglycerides in group 1 the difference was not significant. The other indices showed no significant differences between groups. 
Table 1. Characteristics of the subjects on admission to the study

\begin{tabular}{|c|c|c|c|c|c|c|c|}
\hline Subjects & $\begin{array}{c}\text { Age } \\
\text { (years) }\end{array}$ & $\begin{array}{l}\text { Body-wt } \\
(\mathrm{kg})\end{array}$ & $\begin{array}{c}\text { Body } \\
\text { mass } \\
\text { index } \\
\left(\mathrm{W} / \mathrm{H}^{2}\right)\end{array}$ & $\begin{array}{l}\text { Plasma } \\
\text { cholesterol } \\
(\mathrm{g} / 1)\end{array}$ & $\begin{array}{c}\text { Plasma } \\
\text { triglycerides } \\
(\mathrm{g} / \mathrm{l})\end{array}$ & $\begin{array}{l}\text { Cigarette } \\
\text { smoking } \\
\text { (no./day) }\end{array}$ & $\begin{array}{c}\text { Physical } \\
\text { activity* } \\
\text { (h/d) }\end{array}$ \\
\hline \multicolumn{8}{|c|}{ Group 1} \\
\hline 1 & 46 & 76 & $25 \cdot 7$ & 2.26 & 1.87 & 40 & 2.5 \\
\hline 2 & 33 & 72 & $25 \cdot 8$ & 1.55 & $1 \cdot 05$ & 6 & - \\
\hline 3 & 29 & 70 & $21 \cdot 7$ & 1.87 & 0.49 & - & $2 \cdot 5$ \\
\hline 4 & 41 & 63 & $20 \cdot 6$ & $2 \cdot 08$ & 0.63 & 2 & 1 \\
\hline 5 & 29 & 68 & 22 & 1.67 & 0.63 & 4 & - \\
\hline 6 & 28 & 79 & $26 \cdot 4$ & 1.85 & 0.64 & - & 0.5 \\
\hline 7 & 48 & 79 & $25 \cdot 5$ & $2 \cdot 41$ & $1 \cdot 26$ & 10 & - \\
\hline 8 & 25 & 77 & $23 \cdot 5$ & 1.64 & 0.32 & - & 0.5 \\
\hline 9 & 23 & 67 & $21 \cdot 9$ & $2 \cdot 12$ & 0.54 & - & - \\
\hline 10 & 22 & 63 & $20 \cdot 8$ & $2 \cdot 38$ & 0.80 & - & - \\
\hline Mean & $32 \cdot 4$ & $70 \cdot 6$ & $23 \cdot 4$ & 1.98 & 0.823 & $6 \cdot 2$ & 0.70 \\
\hline $\mathrm{SE}$ & 2.97 & 1.97 & 0.72 & 0.099 & 0.145 & 3.9 & 0.32 \\
\hline \multicolumn{8}{|c|}{ Group 2} \\
\hline 11 & 45 & 81 & $26 \cdot 1$ & 1.82 & 0.63 & - & $2 \cdot 5$ \\
\hline 12 & 44 & 70 & $25 \cdot 7$ & $2 \cdot 22$ & 0.63 & - & - \\
\hline 13 & 29 & 68 & $22 \cdot 2$ & $2 \cdot 15$ & 0.38 & - & 5 \\
\hline 14 & 24 & 75 & $22 \cdot 2$ & 1.58 & 0.45 & 3 & - \\
\hline 15 & 41 & 74 & $26 \cdot 2$ & $1 \cdot 21$ & 0.63 & - & 1.5 \\
\hline 16 & 29 & 63 & $21 \cdot 8$ & 1.52 & 0.53 & 4 & 0.5 \\
\hline 17 & 23 & 65 & 22 & 1.82 & 0.39 & - & - \\
\hline Mean & 33.6 & $70 \cdot 1$ & $23 \cdot 7$ & 1.76 & 0.52 & 1.0 & $1 \cdot 36$ \\
\hline $\mathbf{S E}$ & $3 \cdot 58$ & $2 \cdot 17$ & 0.80 & $0 \cdot 135$ & 0.043 & 0.65 & $0 \cdot 70$ \\
\hline
\end{tabular}

$\mathrm{W} / \mathrm{H}^{2}$, weight $/$ height $^{2}$.

* The various physical activities (cycling, jogging, etc.) are converted to equivalent hours of walking.

\section{Diet}

The study was run on a cross-over basis over a period of 8 weeks. The volunteers were given a daily supplement of two whole eggs and two egg yolks (approximately $1 \mathrm{~g}$ of cholesterol) either with their usual diet or with a low-energy diet. Each subject took part randomly in both dietary periods. In group 1 , ten subjects started with their usual diet supplemented with four eggs/d during the first 4 weeks, and then changed to the egg-supplemented low-energy diet for 4 additional weeks. The dietary periods were reversed in group 2 (seven subjects). All subjects continued their normal daily activities.

The basal food consumption was evaluated for each subject from a $7 \mathrm{~d}$ food recall. The low energy diet, with a $30 \%$ reduction of the energy intake, was then calculated individually. The diets are described in detail in Table 2. Throughout the experimental period, dietary supervision was led by a dietitian.

\section{Lipid analysis}

Changes in body-weight and in plasma lipid content after overnight fasting were determined weekly during the course of the study and additional analysis was performed 7 weeks after the end of the study. Lipids were assayed by enzymic procedures: Boehringer $\mathrm{C}$ system for total cholesterol, Behring Testomar for triglycerides and Biomerieux PAP 150 for phospholipids.

Detailed lipoprotein analysis was carried out before and after each period of dieting. 
Table 2. Composition of diets given to subjects

(Mean values with their standard errors)

\begin{tabular}{|c|c|c|c|c|c|c|c|c|c|c|c|c|c|c|}
\hline \multirow[b]{3}{*}{ Diet } & \multicolumn{4}{|c|}{ Total energy } & \multicolumn{6}{|c|}{ Percentage of total energy } & \multirow{2}{*}{\multicolumn{2}{|c|}{$\mathrm{P}: \mathrm{S}$}} & \multirow{2}{*}{\multicolumn{2}{|c|}{$\begin{array}{c}\text { Cholesterol } \\
(\mathrm{mg} / \mathrm{d})\end{array}$}} \\
\hline & \multicolumn{2}{|c|}{$\mathrm{MJ} / \mathrm{d}$} & \multicolumn{2}{|c|}{$\mathrm{kcal} / \mathrm{d}$} & \multicolumn{2}{|c|}{ Protein } & \multicolumn{2}{|c|}{ Fat } & \multicolumn{2}{|c|}{ Carbohydrate } & & & & \\
\hline & Mean & $\mathrm{SE}$ & Mean & SE & Mean & SE & Mean & SE & Mean & SE & Mean & SE & Mean & SE \\
\hline Usual & $10 \cdot 4$ & $0 \cdot 31$ & 2473 & $73 \cdot 3$ & $13 \cdot 0$ & $0 \cdot 31$ & $42 \cdot 8$ & $1 \cdot 21$ & $44 \cdot 2$ & $1 \cdot 46$ & $0 \cdot 21$ & 0.01 & 406 & $34 \cdot 1$ \\
\hline Usual + eggs & $9 \cdot 8$ & $0 \cdot 30$ & 2345 & $71 \cdot 6$ & $13 \cdot 5$ & 0.31 & $41 \cdot 7$ & $1 \cdot 37$ & $44 \cdot 9$ & 1.63 & $0 \cdot 26$ & 0.01 & 1394 & $8 \cdot 31$ \\
\hline $\begin{array}{l}\text { Low- } \\
\text { energy + eggs }\end{array}$ & $6 \cdot 6$ & $0 \cdot 21$ & 1567 & $48 \cdot 9$ & $16 \cdot 2$ & $0 \cdot 26$ & $45 \cdot 6$ & 0.88 & $38 \cdot 2$ & 0.97 & 0.29 & 0.01 & 1337 & $5 \cdot 12$ \\
\hline
\end{tabular}

$\mathbf{P}: \mathbf{S}$, polyunsaturated : saturated fatty acids.

Venous blood samples were collected after overnight fasting, in vacutainer tubes containing EDTA $(1 \mathrm{mg} / \mathrm{ml})$. Plasma was then separated and sodium azide $(0 \cdot 2 \mathrm{~g} / \mathrm{l})$ added.

Plasma apo B (Sievet-Desrumeaux et al. 1979) and apo Al (Sievet-Desrumeaux et al. 1980) were measured by immunonephelometry with Hyland Travenol reagents. The lipoprotein profiles were obtained by means of density-gradient ultracentrifugation according to A. Mougin-Schutz (personal communication). The discontinuous gradient of potassium bromide was prepared by layering the following solutions: $0.5 \mathrm{ml}, \mathrm{d} 1.24 ; 2.5 \mathrm{ml}$, d 1.21 (containing the plasma sample); $2.5 \mathrm{ml}$, d 1.063;2.5 ml, d 1.040;2.5 ml, d 1.018; $1 \mathrm{ml}, \mathrm{d} \mathrm{1.006}$. Ultracentrifugation was performed at $284000 \mathrm{~g}$ at $15^{\circ}$ for $24 \mathrm{~h}$ in a Beckman SW41 rotor and L5-65 ultracentrifuge.

The gradients were then fractionated into $0.5 \mathrm{ml}$ volumes in which the total cholesterol was determined. Overall recovery of cholesterol was 98.9 (SE 0.86) \% (range 85-113\%). Values for the VLDL, low-density-lipoprotein (LDL) and HDL cholesterol were calculated and adjusted to $100 \%$ recovery, assuming identical percentage loss for all fractions. The pure fractions of VLDL, LDL and HDL, checked by agarose gel electrophoresis (Noble, 1968), were pooled and analysed for their composition after 24-h dialysis against $0.15 \mathrm{M}$ sodium chloride. Total cholesterol, triglycerides and phospholipids were measured as described above. Free cholesterol was determined using Boehringer reagent, and proteins were measured according to Lowry et al. (1951).

\section{Statistical analysis}

Student's paired $t$ test was used to assess statistical significance of the difference between the various periods of the dietary treatments.

\section{RESULTS}

As shown in Fig. 1, all subjects exhibited consistent weight reduction (range $1 \cdot 3-4.5 \mathrm{~kg}$ ) over the low-energy diet period, indicating excellent adherence to the diet. The weight reduction was similar in groups 1 and 2; nevertheless, it can be noted that in group 2 the initial weight was not completely recovered by the end of the study.

Changes in the plasma cholesterol level are presented in Fig. 2. During the first 4 weeks of the study, no changes appeared with egg supplementation of the usual diet (group 1). In contrast, a significant increase in plasma cholesterol was observed when the consumption of four eggs daily was associated with a low-energy diet (group 2). There was marked variation between subjects in the plasma cholesterol response and it appears that some 


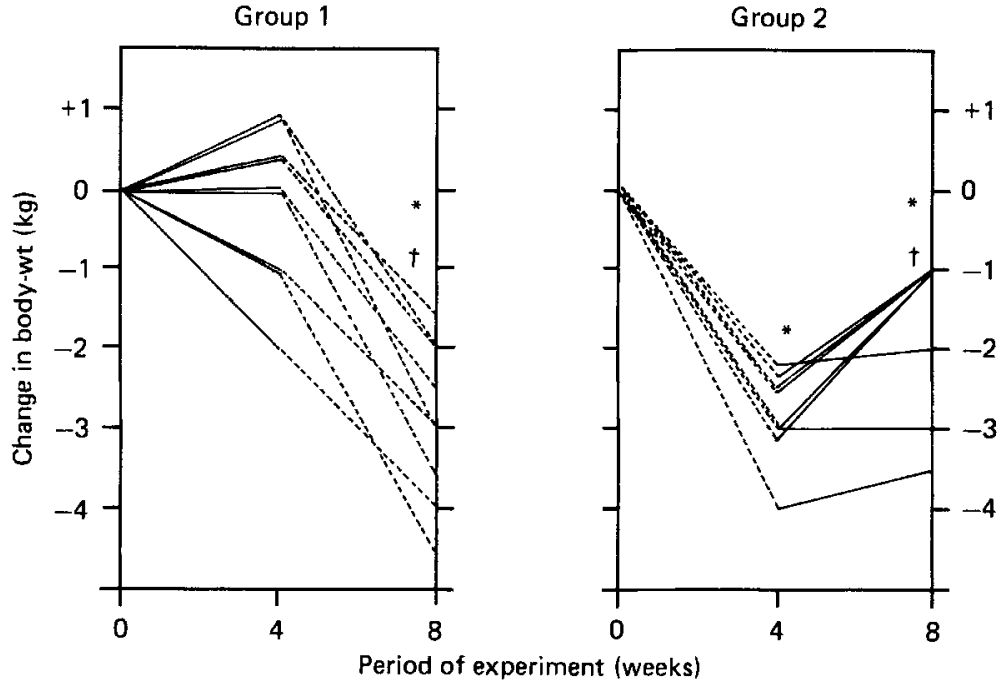

Fig. 1. Individual changes in body-weight in groups 1 and 2 during the periods of egg-supplemented usual diet $(-)$ and of egg-supplemented low-energy diet $(---)$. *† Mean values were statistically significantly different from those for 0 and 4 weeks respectively $(P<0.05)$.

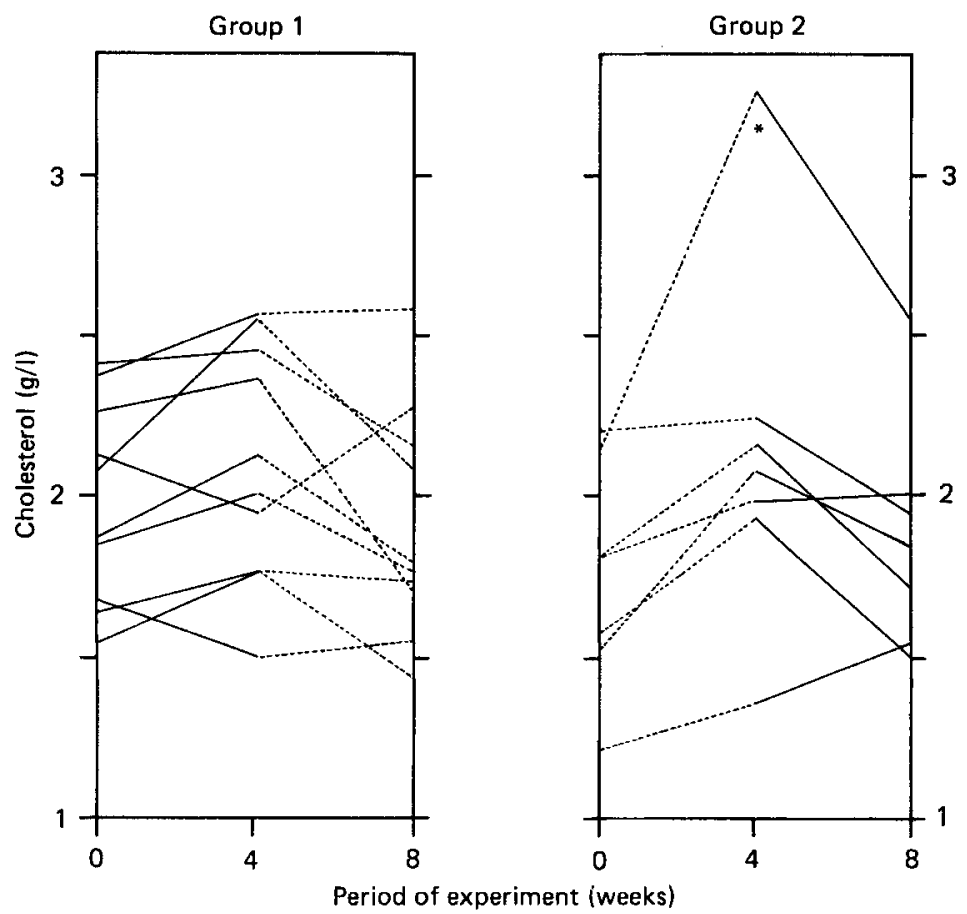

Fig. 2. Individual changes in plasma cholesterol in groups 1 and 2 during the periods of egg-supplemented usual diet $(-)$ and of egg-supplemented low-energy diet $(----)$. *Mean value was statistically significantly different from that for 0 weeks $(P<0 \cdot 05)$. 
individuals could be extremely susceptible to this dietary treatment. Thus in this study one subject exhibited an increase of plasma cholesterol from 2.15 to $3.29 \mathrm{~g} / 1$ after 1 month on the egg-supplemented, low-energy diet. This increase in plasma cholesterol observed in group 2 became almost normalized in the second part of the study when the subjects returned to their usual energy ration. In the subject who appeared the most susceptible, the plasma cholesterol showed a rapid decrease as early as the 1 st week on changing the energy intake, in spite of continuing the consumption of four eggs daily.

In group 1, the interaction between egg supplementation and weight reduction was completely modified by previous adaptation to a high-cholesterol intake. Thus in this group most of the subjects showed a decrease in plasma cholesterol with the low-energy diet although it was not significant (Fig. 2).

In both groups, no marked changes appeared in the plasma triglyceride concentration (Fig. 3). Only two subjects of group 1 who had a high basal level exhibited a decrease in plasma triglycerides following weight reduction.

As shown in Fig. 4, the dietary treatment had no consistent influence on the total plasma phospholipids.

Changes in the distribution of cholesterol between the various lipoprotein fractions obtained after density gradient ultracentrifugation are shown in Fig. 5( $a$ and $b)$ and illustrate the profiles from two subjects of group 1. In this group, egg supplementation of the usual diet induced a slight increase in VLDL cholesterol. When the plasma cholesterol was consistently increased $(2.08$ to $2.55 \mathrm{~g} / 1)$ (Fig. $5(b))$ it should be noted that all fractions were increased, especially the HDL in the density range of HDL2. In the same group the VLDL cholesterol was normalized after weight reduction.

In group 2 (Fig. $5(c$ and $d)$ it appeared that the increase in plasma cholesterol corresponded to increased LDL cholesterol, which could be accompanied by an elevated level of VLDL cholesterol as in Fig. 5(c). The lipoprotein profile almost returned to normal after reversal to the usual energy intake.

Individual variations in the various lipoprotein fractions are shown in Figs. 6, 7 and 8. In group 2 changes in LDL cholesterol were parallel to those of plasma cholesterol with an increase following the low-energy diet and normalization after body-weight recovery (Fig. 6). Changes in VLDL cholesterol were similar although not significant (Fig. 7). In this group no significant changes were observed in HDL cholesterol (Fig. 8).

The opposite effect was shown when the low-energy diet was given after previous adaptation to the intake of four eggs/d (group 1). With this dietary regimen the anomalies induced by egg supplementation disappeared with the low-energy diet. Thus half the subjects presented an increase in VLDL cholesterol accompanied by a decrease in HDL cholesterol following the first part of the diet (Figs. 7 and 8). This was completely normalized after weight reduction. In addition most subjects showed a slight decrease in the LDL cholesterol after weight reduction (Fig. 6).

The changes in lipoprotein composition are shown in Tables 3 and 4. Modifications mainly appeared in the LDL and HDL fractions. The LDL in particular were enriched in cholesterol esters at the expense of decreased protein and triglyceride contents. This appeared as early as the lst month of egg consumption whatever the energy intake. In both groups the HDL also exhibited an enrichment in cholesterol esters which was accompanied by an increase in phospholipid content.

The increase in LDL cholesterol observed in group 2 after the egg-supplemented low-energy diet was not associated with significant changes in the level of plasma apo $\mathbf{B}$, indicating that the increase corresponded to an enrichment in cholesterol of the lipoprotein particles (Fig. 9). In contrast the decrease of LDL cholesterol in group 2 and of VLDL cholesterol in group 1, which appeared in the second part of the diets (weeks 4-8), were 
accompanied by a decreased level of plasma apo B (Fig. 9). No significant changes were observed in the level of plasma apo Al (Fig. 10).

The levels of plasma lipids, cholesterol, triglycerides and phospholipids, measured after an overnight fast 7 weeks after the end of the study were not different from the initial values.

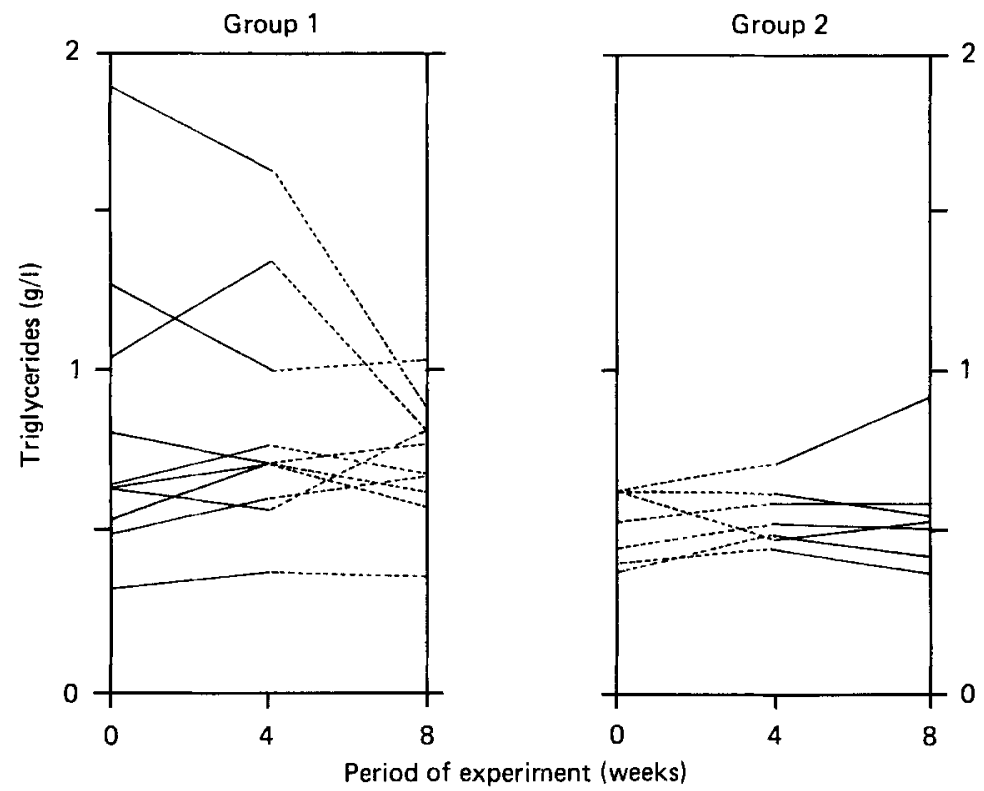

Fig. 3. Individual changes in plasma triglycerides in group 1 and 2 during the periods of egg-supplemented usual diet $(-)$ and of egg-supplemented low-energy diet (-- - - ).

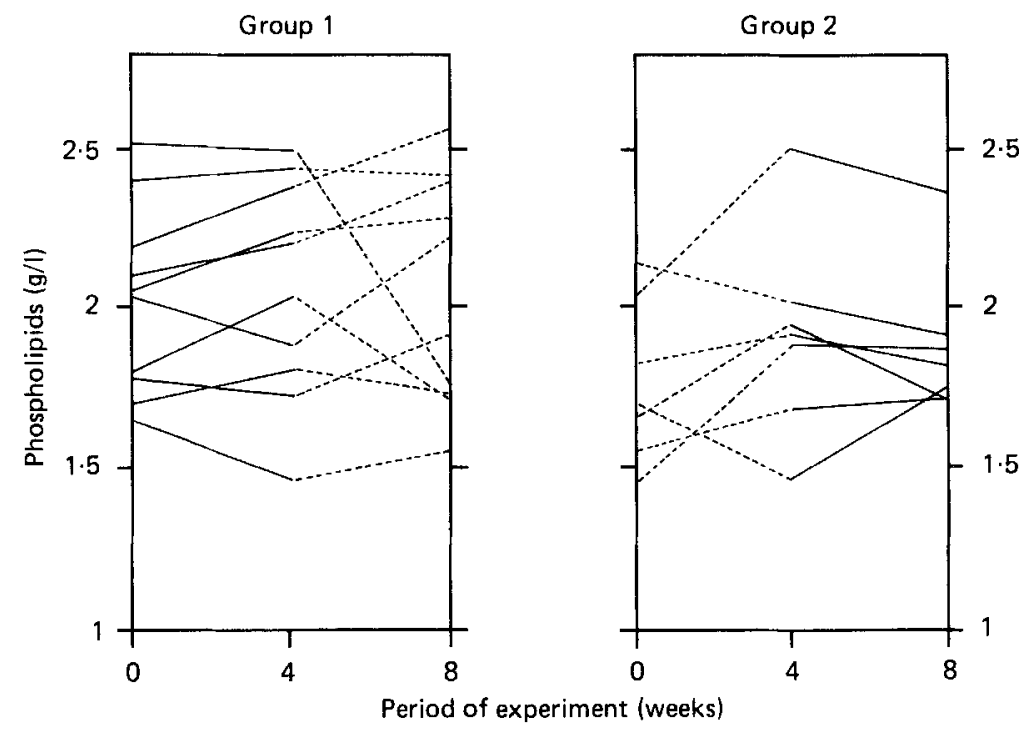

Fig. 4. Individual changes in plasma phospholipids in groups 1 and 2 during the periods of eggsupplemented usual diet $(-)$ and of egg-supplemented low-energy diet $(---\infty)$. 

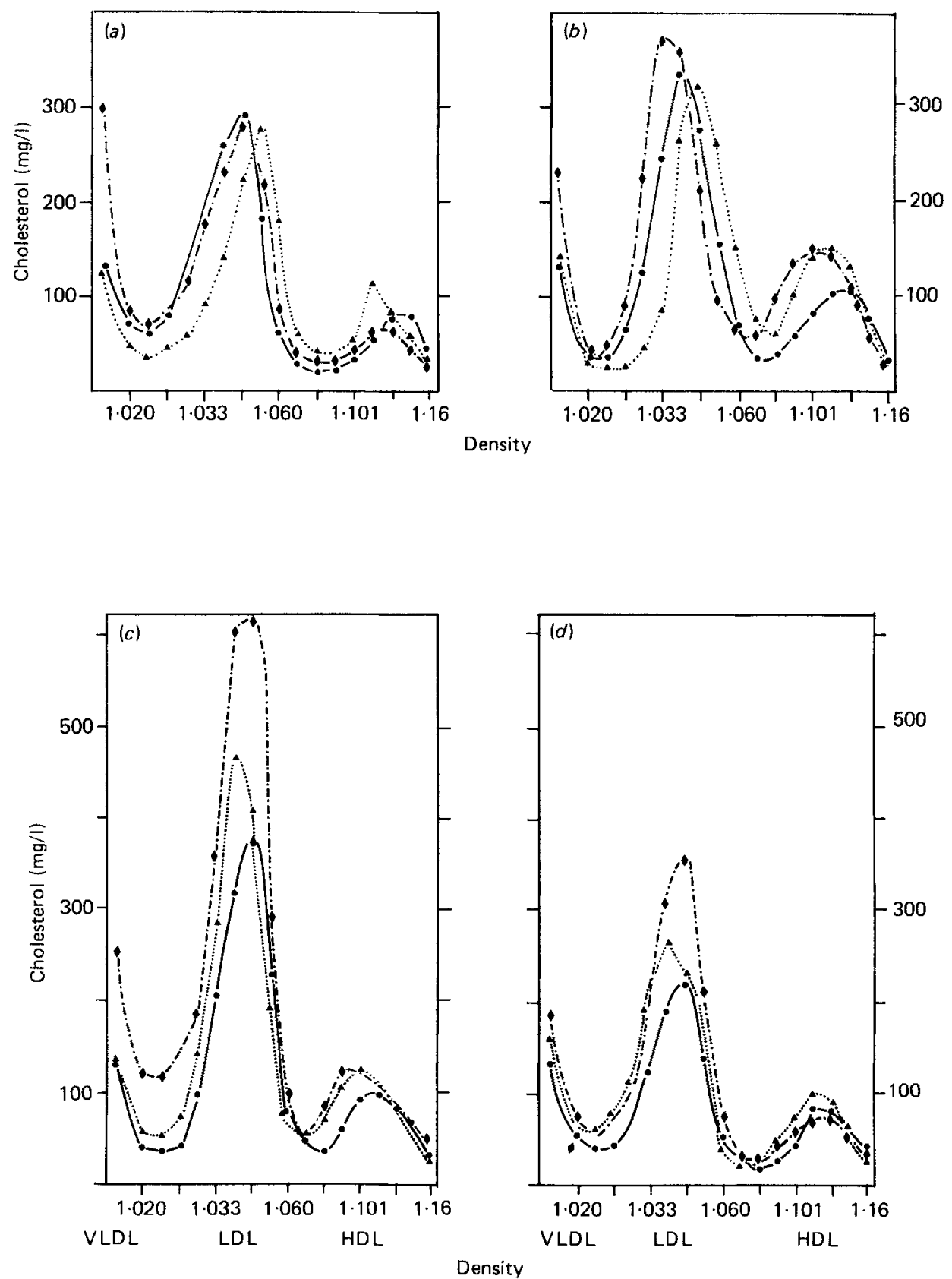

Fig. 5. Distribution of plasma lipoproteins following density gradient ultracentrifugation. (a) and (b), samples from two subjects in group 1 (egg-supplemented usual diet for 4 weeks then egg-supplemented low-energy diet for 4 weeks); $(c)$ and $(d)$, samples from two subjects in group 2 (group 1 regimen in reverse order). $(-), 0$ weeks; $(-\cdot-\cdot-), 4$ weeks; $(\cdots \cdots), 8$ weeks; VLDL, very-low-density lipoprotein; LDL, low-density lipoprotein; HDL, high-density lipoprotein. 


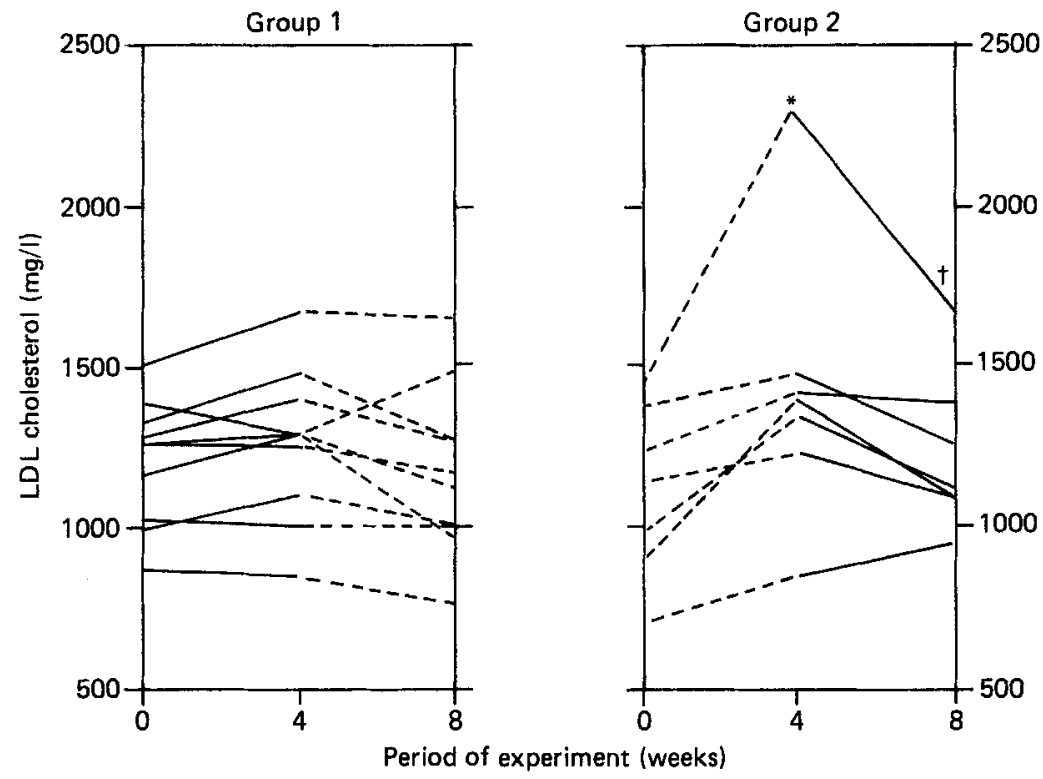

Fig. 6. Individual changes in low-density-lipoprotein (LDL) cholesterol in groups 1 and 2 during the periods of egg-supplemented usual diet $(-)$ and of egg-supplemented low-energy diet $(----)$. *† Mean values were statistically significantly different from those for 0 and 4 weeks respectively $(P<0 \cdot 05)$.

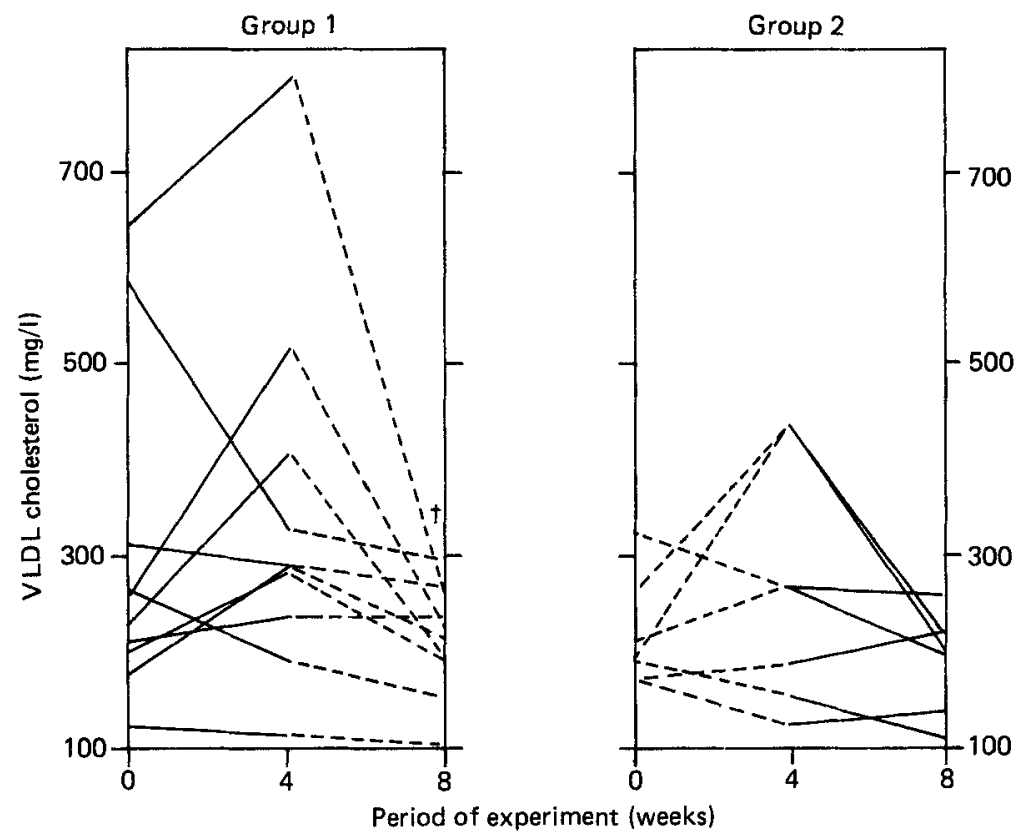

Fig. 7. Individual changes in very-low-density-lipoprotein (VLDL) cholesterol in groups 1 and 2 during the periods of egg-supplemented usual diet $(\longrightarrow)$ and egg-supplemented low-energy diet $(----)$. $\uparrow$ Mean value was statistically significantly different from that for 4 weeks $(P<0.05)$. 


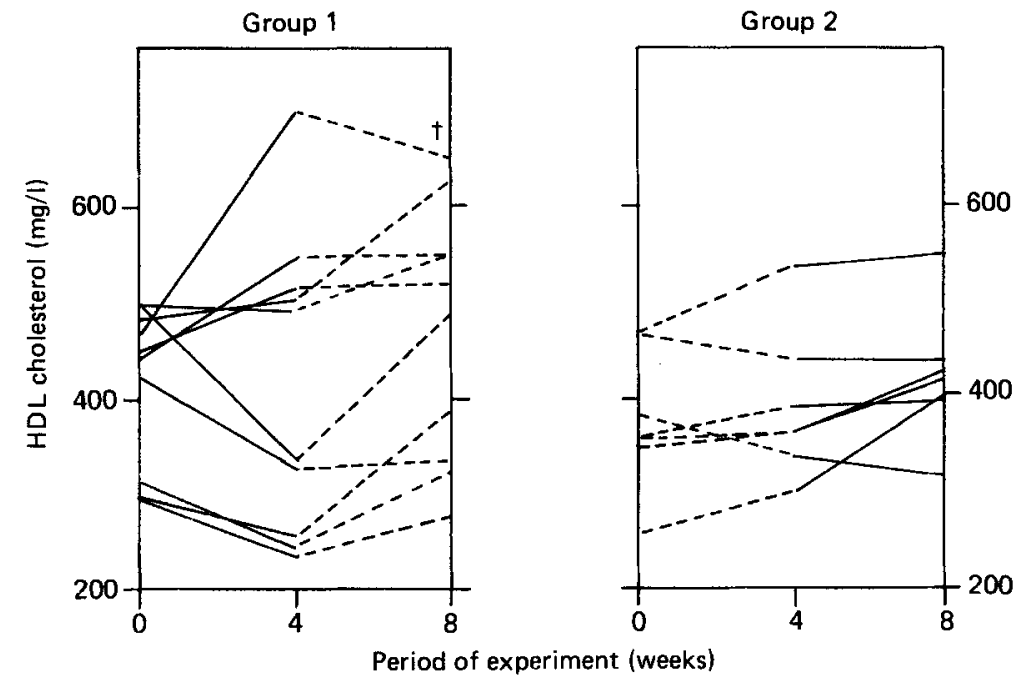

Fig. 8. Individual changes in high-density-lipoprotein (HDL) cholesterol in groups 1 and 2 during the periods of egg-supplemented usual diet $(-)$ and egg-supplemented low-energy diet $(-----)$. $\dagger$ Mean value was statistically significantly different from that for 4 weeks $(P<0.05)$.

Table 3. Percentage changes in plasma lipoprotein composition in group $1 \ddagger$

(Mean values with their standard errors for ten subjects)

\begin{tabular}{|c|c|c|c|c|c|c|c|c|c|c|c|}
\hline \multirow{2}{*}{$\begin{array}{l}\text { Lipo- } \\
\text { protein }\end{array}$} & \multirow{2}{*}{$\begin{array}{l}\text { Period } \\
\text { of } \\
\text { experi- } \\
\text { ment } \\
\text { (weeks) }\end{array}$} & \multicolumn{2}{|c|}{ Protein } & \multicolumn{2}{|c|}{ Triglycerides } & \multicolumn{2}{|c|}{ Phospholipids } & \multicolumn{2}{|c|}{$\begin{array}{c}\text { Cholesterol } \\
\text { esters }\end{array}$} & \multicolumn{2}{|c|}{$\begin{array}{c}\text { Free } \\
\text { cholesterol }\end{array}$} \\
\hline & & Mean & SE & Mean & $\mathrm{SE}$ & Mean & SE & Mean & SE & Mean & SE \\
\hline VLDL & $\begin{array}{l}0 \\
4 \\
8\end{array}$ & $\begin{array}{l}16 \cdot 0 \\
17 \cdot 7 \\
16 \cdot 2\end{array}$ & $\begin{array}{l}1.08 \\
0.95 \\
0.91\end{array}$ & $\begin{array}{l}31 \cdot 2 \\
30 \cdot 4 \\
33 \cdot 5\end{array}$ & $\begin{array}{l}3.09 \\
1.81 \\
1.84\end{array}$ & $\begin{array}{l}20 \cdot 9 \\
20 \cdot 2 \\
21 \cdot 4\end{array}$ & $\begin{array}{l}0.70 \\
0.17 \\
0.35\end{array}$ & $\begin{array}{l}20 \cdot 2 \\
22 \cdot 4 \\
19 \cdot 9\end{array}$ & $\begin{array}{l}1.78 \\
0.94 \\
1.25\end{array}$ & $\begin{array}{c}11 \cdot 3 \\
9 \cdot 24 \\
9 \cdot 09\end{array}$ & $\begin{array}{l}0.31 \\
0.25 \\
0.25\end{array}$ \\
\hline LDL & $\begin{array}{l}0 \\
4 \\
8\end{array}$ & $\begin{array}{l}25 \cdot 4 \\
23 \cdot 5^{*} \\
22 \cdot 7^{*}\end{array}$ & $\begin{array}{l}0.62 \\
0.33 \\
0.66\end{array}$ & $\begin{array}{l}6 \cdot 77 \\
4 \cdot 81 \\
5 \cdot 34^{*}\end{array}$ & $\begin{array}{l}0.60 \\
0.72 \\
0.33\end{array}$ & $\begin{array}{l}23 \cdot 8 \\
21 \cdot 9 \\
22 \cdot 5\end{array}$ & $\begin{array}{l}0.63 \\
0.24 \\
0.51\end{array}$ & $\begin{array}{l}30 \cdot 5 \\
38 \cdot 2^{*} \\
40 \cdot 6^{*}\end{array}$ & $\begin{array}{l}1.94 \\
0.47 \\
1.19\end{array}$ & $\begin{array}{l}13 \cdot 5 \\
10 \cdot 7^{*} \\
11 \cdot 3^{*}\end{array}$ & $\begin{array}{l}0 \cdot 74 \\
0 \cdot 24 \\
0 \cdot 22\end{array}$ \\
\hline HDL & $\begin{array}{l}0 \\
4 \\
8\end{array}$ & $\begin{array}{l}46 \cdot 3 \\
42 \cdot 4^{*} \\
40 \cdot 9^{*}\end{array}$ & $\begin{array}{l}0.64 \\
0 \cdot 51 \\
0 \cdot 82\end{array}$ & $\begin{array}{l}11 \cdot 0 \\
9 \cdot 55 \\
4 \cdot 53^{*} \dagger\end{array}$ & $\begin{array}{l}0.80 \\
0.66 \\
0.35\end{array}$ & $\begin{array}{l}21 \cdot 6 \\
25 \cdot 1^{*} \\
28 \cdot 5^{*} \dagger\end{array}$ & $\begin{array}{l}0.64 \\
0.58 \\
0.67\end{array}$ & $\begin{array}{l}18 \cdot 5 \\
20 \cdot 1 \\
22 \cdot 7^{*}+\end{array}$ & $\begin{array}{l}0.81 \\
0.50 \\
0.56\end{array}$ & $\begin{array}{l}2.59 \\
2.90 \\
3 \cdot 38^{*}\end{array}$ & $\begin{array}{l}0 \cdot 11 \\
0 \cdot 14 \\
0.18\end{array}$ \\
\hline
\end{tabular}

VLDL, very-low-density lipoprotein; LDL, low-density lipoprotein; HDL, high-density lipoprotein.

${ }^{*}+$ Mean values were significantly different from those at 0 and 4 weeks respectively $(P<0.05)$.

$\ddagger$ Egg-supplemented usual diet for 4 weeks, then egg-supplemented low-energy diet for 4 weeks. 
Table 4. Percentage changes in plasma lipoprotein composition in group $2 \ddagger$

(Mean values with their standard errors for seven subjects)

\begin{tabular}{|c|c|c|c|c|c|c|c|c|c|c|c|}
\hline \multirow{2}{*}{$\begin{array}{l}\text { Lipo- } \\
\text { protein }\end{array}$} & \multirow{2}{*}{$\begin{array}{l}\text { Period } \\
\text { of } \\
\text { experi- } \\
\text { ment } \\
\text { (weeks) }\end{array}$} & \multicolumn{2}{|c|}{ Protein } & \multicolumn{2}{|c|}{ Triglycerides } & \multicolumn{2}{|c|}{ Phospholipids } & \multicolumn{2}{|c|}{$\begin{array}{c}\text { Cholesterol } \\
\text { esters }\end{array}$} & \multicolumn{2}{|c|}{$\begin{array}{c}\text { Free } \\
\text { cholesterol }\end{array}$} \\
\hline & & Mean & $\mathrm{SE}$ & Mean & SE & Mean & SE & Mean & $\mathrm{SE}$ & Mean & $\mathrm{SE}$ \\
\hline VLDL & $\begin{array}{l}0 \\
4 \\
8\end{array}$ & $\begin{array}{l}17 \cdot 8 \\
20 \cdot 0 \\
17 \cdot 3\end{array}$ & $\begin{array}{l}0.75 \\
1.74 \\
1.28\end{array}$ & $\begin{array}{l}28 \cdot 2 \\
23 \cdot 7 \\
30 \cdot 1+\end{array}$ & $\begin{array}{l}2 \cdot 23 \\
2 \cdot 41 \\
2 \cdot 21\end{array}$ & $\begin{array}{l}21 \cdot 6 \\
21 \cdot 0 \\
21 \cdot 4\end{array}$ & $\begin{array}{l}0.60 \\
0.59 \\
0.23\end{array}$ & $\begin{array}{l}21 \cdot 1 \\
25 \cdot 2 \\
22 \cdot 0\end{array}$ & $\begin{array}{l}1.80 \\
2 \cdot 25 \\
1.87\end{array}$ & $\begin{array}{c}11 \cdot 3 \\
10 \cdot 1 \\
9 \cdot 28\end{array}$ & $\begin{array}{l}0.29 \\
0.35 \\
0.27\end{array}$ \\
\hline LDL & $\begin{array}{l}0 \\
4 \\
8\end{array}$ & $\begin{array}{l}25 \cdot 8 \\
22 \cdot 4^{*} \\
22 \cdot 4^{*}\end{array}$ & $\begin{array}{l}0.84 \\
0.59 \\
0.76\end{array}$ & $\begin{array}{l}6 \cdot 4 \\
5 \cdot 0^{*} \\
4 \cdot 4^{*}\end{array}$ & $\begin{array}{l}0.74 \\
0.50 \\
0.44\end{array}$ & $\begin{array}{l}24 \cdot 0 \\
22 \cdot 1 \\
22 \cdot 3\end{array}$ & $\begin{array}{l}1.19 \\
0.24 \\
0.63\end{array}$ & $\begin{array}{l}30 \cdot 1 \\
38 \cdot 7^{*} \\
42 \cdot 4^{*}+\end{array}$ & $\begin{array}{l}2.92 \\
0.77 \\
1.57\end{array}$ & $\begin{array}{l}13 \cdot 7 \\
11 \cdot 8 \\
11 \cdot 3\end{array}$ & $\begin{array}{l}0.89 \\
0.24 \\
0.46\end{array}$ \\
\hline HDL & $\begin{array}{l}0 \\
4 \\
8\end{array}$ & $\begin{array}{l}48 \cdot 2 \\
41 \cdot 6^{*} \\
43 \cdot 8^{*}\end{array}$ & $\begin{array}{l}1.01 \\
0.79 \\
1.54\end{array}$ & $\begin{array}{l}11 \cdot 0 \\
8 \cdot 43 \\
4 \cdot 06^{* \dagger}+\end{array}$ & $\begin{array}{l}1.07 \\
0.61 \\
0.28\end{array}$ & $\begin{array}{l}19 \cdot 6 \\
25 \cdot 0^{*} \\
26 \cdot 1^{*}\end{array}$ & $\begin{array}{l}0.28 \\
0.46 \\
0.92\end{array}$ & $\begin{array}{l}18 \cdot 7 \\
21 \cdot 7^{*} \\
22 \cdot 8^{*}\end{array}$ & $\begin{array}{l}0.63 \\
0.51 \\
0.67\end{array}$ & $\begin{array}{l}2 \cdot 47 \\
3 \cdot 24^{*} \\
3 \cdot 21^{*}\end{array}$ & $\begin{array}{l}0 \cdot 08 \\
0 \cdot 15 \\
0 \cdot 20\end{array}$ \\
\hline
\end{tabular}

VLDL, very-low-density lipoprotein; LDL, low-density lipoprotein; HDL, high-density lipoprotein.

$*+$ Mean values were significantly different from those at 0 and 4 weeks respectively $(p<0.05)$.

$\ddagger$ Egg-supplemented low-energy diet for 4 weeks, then egg-supplemented usual diet for 4 weeks.

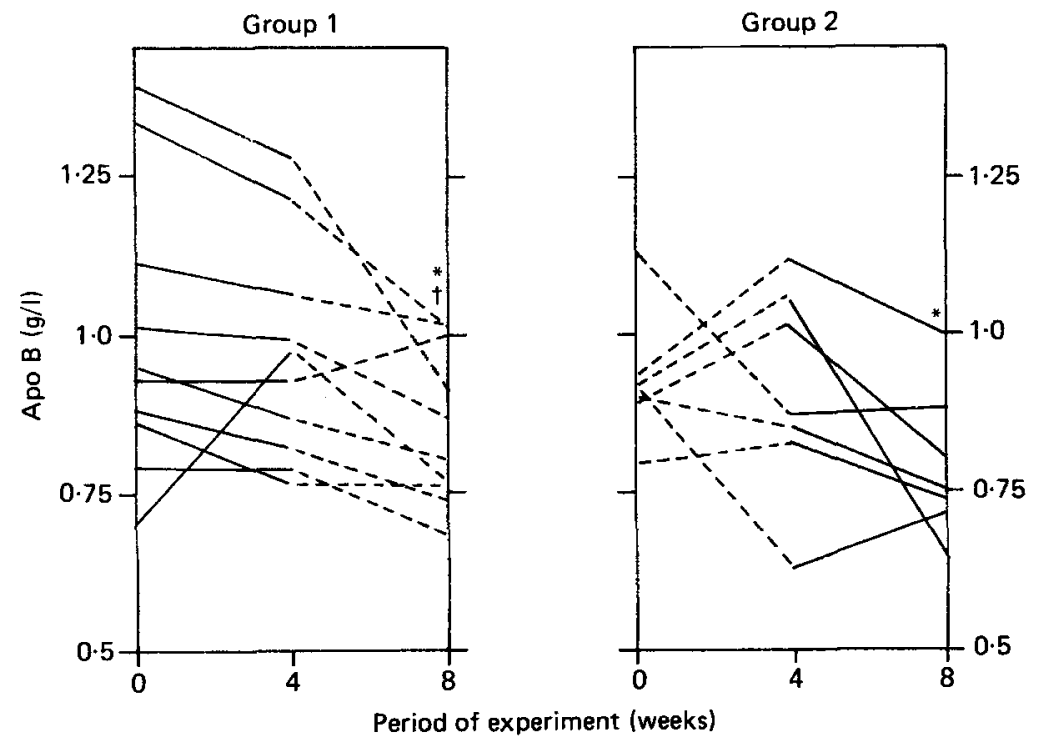

Fig. 9. Individual changes in plasma apo $B$ level in groups 1 and 2 during the periods of egg-supplemented usual diet $(-)$ and egg-supplemented low-energy diet $(--\ldots)$. ${ }^{*} \dagger$ Mean values were statistically significantly different from those for 0 and 4 weeks respectively $(P<0.05)$. 


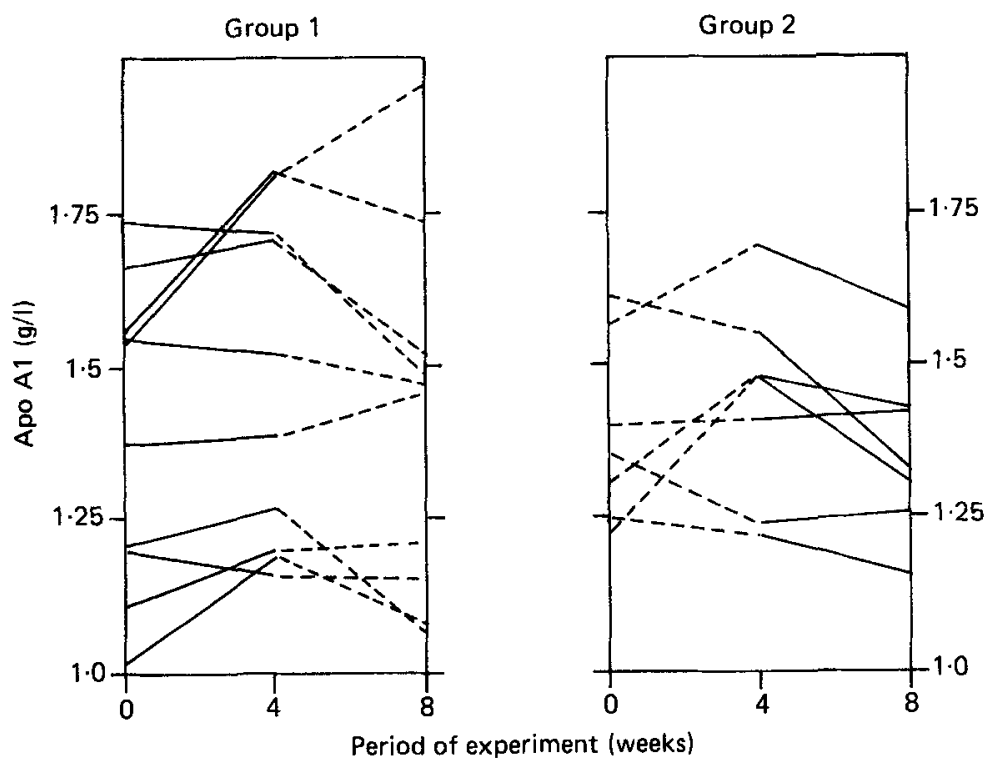

Fig. 10. Individual changes in plasma apo Al level in groups 1 and 2 during the periods of egg-supplemented usual diet (-) and egg-supplemented low-energy diet $(---)^{-}$.

\section{DISCUSSION}

High cholesterol intake provided by four eggs/d had no significant effect on plasma cholesterol when associated with the usual diet; only one subject exhibited a clear increase. This confirms previous studies which showed a wide range of response to increased dietary cholesterol. In the 'responders', the increase in plasma cholesterol corresponds to a concomitant increase in LDL and $\mathrm{HDL}_{2}$ (Tan et al. 1980; Mistry et al. 1981; Schonfeld et al. 1982; Cole et al. 1983). In addition, several studies report the appearance of HDLc (Mahley et al. 1978; Cole et al. 1983). In the present study we also observed an increase in $\mathrm{HDL}_{2}$, accompanying that of the other fractions, in the subject who responded to high-cholesterol intake. In the same group (group 1) a slight increase in VLDL cholesterol accompanied by a decrease in HDL cholesterol were observed in several subjects but the changes were not significant.

In contrast, the low-energy diet markedly decreased the tolerance to dietary cholesterol, resulting in increased plasma cholesterol, when changing from a diet relatively poor in cholesterol to a high-cholesterol intake. The associated changes in lipoprotein profile are characterized by an increase in atherogenic lipoprotein fractions, VLDL and principally LDL, while no changes appeared in the level of HDL.

These results confirm our previous observation concerning the adverse effect of dietary restriction in the rabbit (Lacombe et al. 1983) and in the rat (Corraze et al. 1985a). Nevertheless it should be noted that in humans the main increase in cholesterol appeared in the LDL fraction while in the rabbit, as in the rat, the excess in circulating cholesterol induced by dietary restriction was carried essentially by the VLDL. In fact these results are not conflicting since several studies of the time course of changes in the various lipoprotein fractions as a function of the level of plasma cholesterol have shown that the increase in cholesterol appears first in the LDL and then in the VLDL fractions (Brattsand, 1976; Scholz et al. 1982). In the present experiment only a moderate increase in plasma cholesterol appeared compared with our previous experimental studies in animals. 
An interesting observation was the wide range of variation between individuals in response to associated high-cholesterol intake and weight reduction. In the group which took part in this study we observed the existence of 'high-responders' and 'low-responders'. Furthermore, plasma cholesterol almost returned to normal as early as the 1 st week after changing from the low-energy diet to the usual energy intake, especially in the subject who appeared the most susceptible. This clearly indicates the involvement of weight reduction in the increase in plasma cholesterol observed during the first part of the diet.

The mechanisms responsible for the adverse effect of dietary restriction when associated with the cholesterol-rich diet are under investigation in the rabbit. The results obtained so far indicate that the excess in circulating cholesterol is of dietary origin, since endogenous cholesterol synthesis is almost completely inhibited (Corraze et al. 1985b) but it does not result from more effective intestinal absorption (Corraze et al. 1984). Additional information shows that the abnormal VLDL which accumulates is hepatogenous lipoprotein (Corraze et al. 1985c). Our studies are currently focused on VLDL metabolism.

The interaction between dietary cholesterol and weight reduction was completely different when the dietary regimens were reversed as in group 1 . In this case weight reduction improved the lipoprotein pattern, with a decrease in VLDL cholesterol and an increase in HDL cholesterol. This confirms the results obtained in several studies on obese subjects where the lipoprotein pattern was seen to be improved after acute weight reduction (Bolzano et al. 1979; Hendrikx et al. 1979; Taskinen \& Nikkila, 1979; Schouten et al. 1981; Wechsler et al. 1981; Wolf \& Grundy, 1983; Zimmerman et al. 1984). Nevertheless the possible existence of another type of response was suggested by careful analysis of these results. In fact the direction of changes was clearly related to the initial level and in normolipidaemic individuals the plasma triglycerides and cholesterol were increased by fasting whereas they decreased in fasting hyperlipidaemic subjects (Bolzano et al. 1979; Hendrikx et al. 1979). Similarly, in the present study, the direction of changes was also related to the basal plasma lipids since the beneficial effects of dietary restriction appeared only after a previous period of high-cholesterol intake which had resulted in slight disturbances in the lipoprotein pattern.

Thus there are two types of response to weight reduction which could be related to the previous plasma lipid level. The possible existence of great susceptibility to high-cholesterol intake and a low-energy diet calls for special attention to be paid to the cholesterol content of low-energy or 'slimming' diets. Various 'slimming' diets were recently analysed (Pi-Sunyer, 1982). It appears that some diets, especially the Atkins (1972) and the Stillman \& Baker (1967) diets which are very famous, are rich in cholesterol. Although these two diets represent excessive situations, in low-energy diets it is generally advised to preserve the intake of foods rich in proteins such as meat, eggs and fish, which also contain variable amounts of cholesterol, resulting in situations very close to our experimental conditions. Thus in the light of our results, we think that it would be generally better to reduce the consumption of animal products when following a 'slimming' diet.

An additional argument results from the fact that the appearance of abnormal LDL is observed following egg supplementation of the diet, whatever the energy intake, and cholesterol-rich lipoproteins are known to be atherogenic. Studies on cultured smooth muscles cells show that the LDL isolated from hypercholesterolaemic animals stimulate cell proliferation (Fless et al. 1982) and intracellular cholesterol accumulation (Mahley et al. 1977; St-Clair et al. 1978, 1983; Eisele et al. 1980). In addition a positive correlation has been found between the cholesterol ester content of the LDL and the severity of atherosclerosis in monkeys (Rudel et al. 1979, 1981).

In conclusion, the results confirm the existence in humans of an interaction between weight reduction and high-cholesterol intake. The hypercho'esterolaemic effect of egg 
supplementation is revealed in the case of low-energy diets. Nevertheless the opposite effect of weight reduction is observed with previous adaptation to high cholesterol intake. Thus the present study indicates that the effect of one factor depends not only on other associated factors but also on the dietary regimen.

The authors wish to express their deepest gratitude to the volunteers for their participation in this study. The technical assistance of G. Molinier and J. Rolland is also gratefully acknowledged.

\section{REFERENCES}

Applebaum-Boyden, D., Hazzard, W. R., Cain, J., Cheung, M. C., Kushwaha, R. S. \& Albers, J. J. (1979). Atherosclerosis 33, 385-396.

Atkins, R. C. (1972). Dr Atkins' Diet Revolution. New York: McKay.

Avogaro, P., Cazzolato, G., Bittolo Bon, G., Quinci, G. B. \& Chinello, M. (1978). Atherosclerosis 31, 85-91.

Barrett-Connor, E., Witztum, J. L. \& Holdbrook, M. (1983). American Journal of Epidemiology 117, $186-192$.

Beveridge, J. M. T., Connell, W. F., Haust, H. A. \& Mayer, G. A. (1960). Journal of Nutrition 71, 61-65.

Bolzano, K., Haslauer, F. \& Krempler, F. (1979). Atherosclerosis 33, 171-180.

Brattsand, R. (1976). Atherosclerosis 23, 97-110.

Bronsgeest-Schoute, D. C., Hermus, R. J. J., Dallinga-Thie, G. M. \& Hautvast, J. G. A. J. (1979). American Journal of Clinical Nutrition 32, 2188-2192.

Cole, T. G., Patch, W., Kuisk, B., Gonen, B. \& Schonfeld, G. (1983), Journal of Clinical Endocrinology and Metabolism 56, 1108-1119.

Corraze, G., Lacombe, C. \& Nibbelink, M. (1984). Lipids 19, 812-814.

Corraze, G., Lacombe, C. \& Nibbelink, M. (1985a). Nutrition Research 5, 781-787.

Corraze, G., Lacombe, C. \& Nibbelink, M. (1985b). Experimental and Molecular Pathology 43, $260-267$.

Corraze, G., Lacombe, C. \& ỉvibbelink, M. (1985c). Lipids 20, 751-756.

Eisele, B., Bates, S. R. \& Wissler, R. W. (1980). Atherosclerosis 36, 9-24.

Flaim, E., Ferreri, L. F., Thye, F. W., Hill, J. E. \& Ritchey, S. J. (1981). American Journal of Clinical Nutrition 34, $1103-1108$

Fless, G. M., Kirchausen, T., Fischer-Dzoga, K., Wissler, R. W. \& Scanu, A. M. (1982). Atherosclerosis 41, 171-183.

Flynn, M. A., Nolph, G. B., Flynn, T. C., Kahrs, R. \& Krause, G. (1979). American Journal of Clinical Nutrition 32, $1051-1057$.

Hendrikx, A., Boni, L., Kieckens, L., Meulepas, E. \& De Moor, P. (1979). American Journal of Clinical Nutrition 32, 1799-1804.

Keys, A., Fidanza, F., Karvonen, M. J., Kimura, N. \& Taylor, H. L. (1972). Journal of Chronic Diseases 25, 329-343.

Kummerow, F. A., Kim, Y., Hull, M. D., Pollaro, J., Ilinov, P., Dorossiev, O. L. \& Valek, J. (1977). American Journal of Clinical Nutrition 30, 664-673.

Lacombe, C., Corraze, G. \& Nibbelink, M. (1983). Lipids 18, 306-312.

Lin, D. S. \& Connor, W. E. (1980). Journal of Lipid Research 21, 1042-1052.

Lowry, O. H., Rosebrough, H., Farr, A. L. \& Randall, R. S. (1951). Journal of Biological Chemistry 193, $265-275$. Mahley, R. W., Innerarity, T. L., Bersot, T. P., Lipson, A. \& Margolis, S. (1978). Lancet ii, 807-809.

Mahley, R. W., Innerarity, T. L., Weisgraber, K. H. \& Fry, D. L. (1977). American Journal of Pathology 87, 205-226.

Mattson, F. H., Erickson, B. A. \& Kligman, A. M. (1972). American Journal of Clinical Nutrition 25, 589-594.

Mistry, P., Miller, N. E., Laker, M., Hazzard, W. R. \& Lewis, P. (1981). Journal of Clinical Investigations 67, $493-502$.

Nestel, P. J. \& Payser, A. (1976). Metabolism 25, 1591-1599.

Noble, R. P. (1968). Journal of Lipid Research 9, 693-700.

Pi-Sunyer, F. X. (1982). Bulletin of the New York Academy of Medicine 58, 263-274.

Porter, M. W., Yamanaka, W., Carlson, S. D. \& Flynn, M. A. (1977). American Journal of Clinical Nutrition 30, $490-495$.

Quintao, E., Grundy, S. M. \& Ahrens, E. H. (1971). Journal of Lipid Research 12, 233-247.

Roberts, S. L., McMurry, M. P. \& Connor, W. E. (1981). American Journal of Clinical Nutrition 34, $2092-2099$.

Rudel, L. L., Leathers, C. W., Bond, M. G. \& Bullock, B. C. (1981). Arteriosclerosis 1, 144-145.

Rudel, L. L., Shah, R. \& Greene, D. G. (1979). Journal of Lipid Research 20, 55-65.

St-Clair, R. W. \& Leight, M. A. (1978). Biochimica et Biophysica Acta 530, 279-291.

St-Clair, R. W., Greenspan, P. \& Leight, M. (1983). Arteriosclerosis 3, 77-86.

Scholz, K. E., Beynen, A. C. \& West, C. E. (1982). Atherosclerosis 44, 85-97. 
Schonfeld, G., Patsch, W., Rudel, L. L., Nelson, C., Epstein, M. \& Olson, R. E. (1982). Journal of Clinical Investigation 69, 1072-1080.

Schouten, J. A., Van Gent, C. M., Popp-Snijders, C., Van Der Ven, E. A. \& Van Der Voort, H. A. (1981). International Journal of Obesity 5, 333-340.

Sievet-Desrumeaux, C., Dedomder-Decoopman, E., Fruchart, J. C., Dewailli, P. \& Sezille, G. (1979). Clinica Chimica Acta 95, 405-408.

Sievet-Desrumeaux, C., Dedomder-Decoopman, E., Fruchart, J. C., Dewailli, P., Sezille, G. \& Jaillard, J. (1980). Clinica Chimica Acta 107, 145-148.

Slater, G., Mead, J., Dhopeshwarkar, G. \& Alfin-Slater, R. B. (1976). Nutrition Reports International 14, $249-260$.

Stillman, I. M. \& Baker, S. S. (1967). The Doctor's Quick Weight Loss Diet. Englewood Cliffs, New Jersey: Prentice Hall.

Tan, M. H., Dickinson, M. A., Albers, J. J., Havel, R. J., Cheung, M. C. \& Vigne, J. L. (1980). American Journal of Clinical Nutrition 33, 2559-2565.

Taskinen, M. R. \& Nikkila, E. A. (1979). Atherosclerosis 32, 289-299.

Wechsler, J. G., Hutt, V., Wenzel, H., Klor, H. U. \& Ditschuneit, H. (1981). International Journal of Obesity 5 , 325-331.

Wolf, R. N. \& Grundy, S. M. (1983). Arteriosclerosis 3, 160-169.

Zimmerman, J., Kaufmann, N. A., Fainaru, M., Eisenberg, S., Oschry, Y., Friedlander, Y. \& Stein, Y. (1984). Arteriosclerosis 4, 115-123. 